\title{
Vorbemerkung \\ zur 4. Auflage von 1974
}

Nachdem 1967 die 3., durchgesehene und ergänzte Auflage des „Wörterbuches der ugaritischen Sprache" erschienen war, zeigte sich in den darauffolgenden Jahren, da $B$ die Nachfrage nach diesem Werk noch nicht befriedigt werden konnte.

Der Herausgeber, Herr Prof. Dr. OtTo Eissfeldi, hat mit großer Akribie sowohl die begonnene Arbeit des Autors, Herrn Prof. Dr. JoSEPH AISTLEITNER, als dieser 1960 verstarb, zu Ende geführt als auch die 2. und 3. Auflage durchgesehen und die inzwischen erschienene Literatur auf diesem Gebiet in das Wörterbuch aufgenommen. Nach seinem Tode im Jahre 1973 sehen wir uns nun auf Grund zahlreicher Nachfragen von Instituten, Bibliotheken und Wissenschaftlern gezwungen, einen unveränderten Nachdruck der 3. Auflage herauszugeben, und hoffen, damit sowohl im Interesse der zukünftigen Benutzer dieses Wörterbuches als auch des Autors bzw. Herausgebers gehandelt $\mathrm{zu}$ haben.

Berlin, im April 1974 .

Der Verlag 